\title{
EFFECTS OF CONCENTRATION AND SOLVENT COMPOSITION ON THE ELECTRICAL CONDUCTIVITY OF SODIUM BROMIDE IN PURE WATER AND ETHANOL-WATER MIXED SOLVENT MEDIA
}

\author{
Ajaya Bhattarai*, Sanjay Neupane \\ Department of Chemistry, Mahendra Morang Adarsh Multiple Campus, Tribhuvan \\ University, Biratnagar, Nepal \\ Corresponding author: bkajaya@yahoo.com \\ Received 17 January, 2012; Revised 21 August, 2012
}

\begin{abstract}
Precise measurements on the conductivity of Sodium Bromide in pure water and ethanol-water mixed solvent media containing $0.10,0.20,0.30,0.40,0.50$ and 0.60 volume fractions of ethanol at room temperature are reported. The concentrations were varied from $\sim 0.010$ to $\sim 0.10 \mathrm{~mol} . \mathrm{L}^{-1}$. The results showed a sharp increase in the conductivity with increasing electrolyte concentration. The conductivity of electrolyte decreases with increase in the amount of ethanol.
\end{abstract}

Keywords: mixed solvent media, conductivity, sodium bromide, ethanol

\section{INTRODUCTION}

The conductivity measurements provide important information on ion-ion and ion-solvent interactions [1]. Studies on electrolytic conductance in mixed solvents can provide useful information and sensitive indications of ion-solvent and ion-ion interactions and solvent structure. The effect of ion association on the conductance behavior of electrolytes has been a subject of extensive investigation. Although numerous conductance measurements have been reported in the literature, such studies in mixed solvents are relatively rare [2]. In recent, several studies have reported that the nature of the spherical ions, having a large variation in size in aqueous mixtures of the alcohols, has received considerable attention [3].

It was reported in the previous work [4] that potassium halides are structure breakers in ethanol-water mixtures and the maximum in breaking power occurs at 0.1 mole fraction of ethanol. The conductance of Sodium nitrate in ethanol - water mixtures was measured at $308.15 \mathrm{~K}$ in 1979 [5]. The measurement of conductance of Sodium Chloride in pure water and ethanol-water mixed solvent media has been done [6]. Recently, the conductance of Potassium Bromide in pure water and ethanol-water mixed solvent media has been measured in our laboratory [7]. No work has been done earlier on the effects of Concentration and solvent composition on the electrical conductivity of Sodium Bromide in ethanol-water mixed solvent media. But we have been able to publish the abstract [8] on effects of concentration and solvent composition on the electrical conductivity of Sodium Bromide in pure water and ethanol-water mixed solvent media. This paper deals with the electrical conductivity of Sodium Bromide in pure water and ethanol-water mixtures covering a range of dielectric constant values at room temperature $(303.15 \mathrm{~K})$ as a full manuscript.

\section{EXPERIMENTAL METHODS}

Ethanol (E. Merck, India) was used for the experimental works. The purified solvent had a density of $0.78097 \mathrm{~g} . \mathrm{cm}^{-3}$ and a co-efficient of viscosity of $0.9490 \mathrm{mPa} . \mathrm{s}$ at $303.15 \mathrm{~K}$; these values are in good agreement with the literature values [9]. Distilled water with a specific conductance less than $10^{-6} \mathrm{~S} . \mathrm{cm}^{-1}$ at $303.15 \mathrm{~K}$ was used for the preparation of the mixed solvents. The physical properties of ethanol-water mixed solvents used in this study at 
$303.15 \mathrm{~K}$ were taken from the published works $[3,6,7,10]$.

Sodium Bromide $(\mathrm{NaBr})$ employed in these investigations was purchased from SD Fine Chem Limited, Mumbai, India. Conductance measurements were carried out on a PyeUnicam PW 9509 conductivity meter at a frequency of $2000 \mathrm{~Hz}$ using a dip-type cell with a cell constant of $1.15 \mathrm{~cm}^{-1}$ and having an uncertainty of $0.01 \%$. The cell was calibrated by the method of Lind and co-workers in 1959[11], using aqueous potassium chloride solution. The measurements were made at room temperature. The details of the experimental procedure have been described earlier $[12,13]$. Several independent solutions were prepared and runs were performed to ensure the reproducibility of the results. Due correction was made for the specific conductance of the solvent by subtracting the specific conductance of the relevant solvent medium from those of the electrolyte solutions. In order to avoid moisture pickup, all solutions were prepared in a dehumidified room with utmost care. In all cases, the experiments were performed in three replicates.

\section{RESULTS AND DISCUSSION}

The structures of liquid alcohols are much simpler than that of water. They associate much less strongly, and form polymeric $\mathrm{H}$-bonded chains, rather than large cluster, which rarely contain 5 to 7 molecules for sterically hindered alcohols [14]. When alcohol and water are mixed there is a minute but measurable heat of solution that is evident. The hydrogen bonding and closer packing of the molecules by the attraction allows a larger number of molecules of the hydrated alcohol to fit into the same space, thus decreasing the overall volume. The density is decreased with the increase of alcohol content for the ethanol-water mixed solvent system. This behaviour has been found to be similar in the literatures $[15,16$, 17]. As a liquid becomes warmer, the molecules spread out more. When the molecules are more spread out, the substance is less dense, as the specific gravity is lower.

In ethanol-water mixtures, solvent-solvent interactions play a considerable part and properties of these mixtures cannot always be interpreted on the basis of continuous miscibility of the components in all mixtures. These mixtures possess also pronounced structures which vary with temperature and ethanol content.

The variation in the density, dielectric constant and viscosity with ethanol content are found similar with our earlier published works [6-7]. The experimental specific conductivities of Sodium Bromide as a function of the salt concentration $\left(\mathrm{c}_{\mathrm{s}}\right)$ at $303.15 \mathrm{~K}$ of pure water and six different ethanol-water mixtures (containing 0.10, 0.20, 0.30, 0.40, 0.50 and 0.60 volume fractions of ethanol) are depicted in Fig. 1 and shows the specific conductivities exhibit a sharp increase with increasing concentration within the concentration range investigated. The increase in the conductance with concentration is due to an increase in the number of ions per unit volume of the solution.

Obviously, the concentration dependence of the specific conductivity follows the same pattern at all solvent composition investigated. In fact, the variations of specific conductivity with electrolyte concentrations are always found to be linear. We, therefore, determined the slopes (Table 1). The possible explanation for the positive slopes in the present mixed solvent media may be that the counter ion binding would become quite appreciable in these media as the concentration of the electrolyte is increased, thereby weaker ion-solvent interactions. As a consequence, contraction of the solvent would be gradually lowered with increasing concentration of the electrolyte, resulting in a net positive volume change per mol of the added electrolyte. Moreover, the slopes are found to decrease in the mixed solvent media 
become richer in ethanol.

The relative permittivity of the medium decreased at a given temperature with increasing in the ethanol content and this trend has also been seen in the conductivity study $[18,19,20,21$, 22] of methanol content in water. The conductance decreases with increase of alcohol content for the studied ethanol-water mixed solvent system. The presence of ethanol reduces the dielectric constant of the solvent phase and makes easier for the formation of ion-pairs in the solution phase. In other words, in solvents of low dielectric constants, having small ionizing effect on the electrolytes, the electrostatic forces between oppositely charged ions would be appreciable and conductance value will have small value. However, solvents with high dielectric constants yield more conducting solutions.

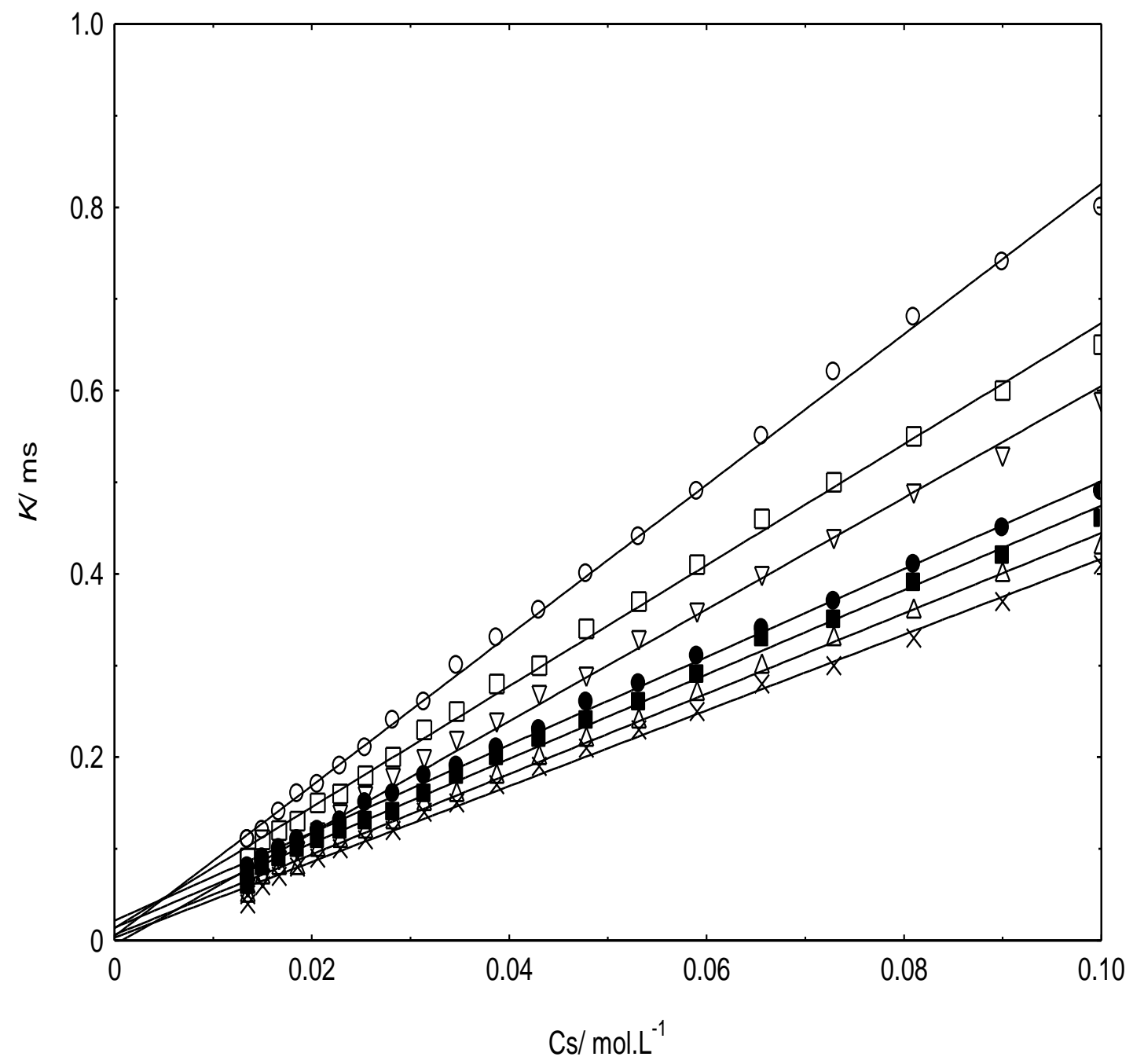

Figure 1 Specific conductivities of $\mathrm{NaBr}$ as a function of the salt concentration $\left(\mathrm{c}_{\mathrm{s}}\right)$ in 303.15 $\mathrm{K}$ : open circles, open squares, open opposite triangles, closed circle,closed squares, open triangles and crosses represent pure water and $0.10,0.20,0.30,0.40,0.50$ and 0.60 volume fractions of ethanol in the solvent mixture respectively.(Solid lines - fitted graphs). 
Table 1- Experimental slopes and the correlation coefficients of fits (as $\mathrm{r}^{2}$ ) of sodium bromide in figure 1 with pure water and Ethanol-Water mixtures at $303.15 \mathrm{~K}$.

\begin{tabular}{|c|c|c|c|}
\hline $\mathrm{T} / \mathrm{K}$ & slope & $\mathrm{r}^{2}$ & $\mathrm{D}$ \\
\hline \multicolumn{4}{|c|}{ Pure water } \\
\hline 303.15 & 8.21 & 0.998 & 76.54 \\
\hline \multicolumn{4}{|c|}{0.10 volume fraction of ethanol } \\
\hline 303.15 & 6.60 & 0.997 & 72.00 \\
\hline \multicolumn{4}{|c|}{0.20 volume fraction of ethanol } \\
\hline 303.15 & 6.10 & 0.995 & 67.32 \\
\hline \multicolumn{4}{|c|}{0.30 volume fraction of ethanol } \\
\hline 303.15 & 4.80 & 0.998 & 62.07 \\
\hline \multicolumn{4}{|c|}{0.40 volume fraction of ethanol } \\
\hline 303.15 & 4.61 & 0.997 & 56.89 \\
\hline \multicolumn{4}{|c|}{0.50 volume fraction of ethanol } \\
\hline 303.15 & 4.38 & 0.997 & 51.48 \\
\hline \multicolumn{4}{|c|}{0.60 volume fraction of ethanol } \\
\hline 303.15 & 4.13 & 0.996 & 45.77 \\
\hline
\end{tabular}

\section{CONCLUSIONS}

The following conclusions have been drawn from the above results and discussion. Experimental results for the specific conductivity of solution of sodium bromide in ethanolwater mixed solvent media have been presented as a function of salt concentration and different percentage composition of (ethanol + water) mixed solvent media. The specific conductivities are found to increase with increasing concentration over the entire concentration range investigated whereas the specific conductivities of sodium bromide decrease with decreasing dielectric constant of solvent composition at temperature $303.15 \mathrm{~K}$.

\section{ACKNOWLEDGEMENTS}

The authors are grateful to Professor Dr. Sujeet Kumar Chatterjee at the department of Chemistry, Mahendra Morang Adarsh Multiple Campus, Tribhuvan University, Biratnagar, Nepal for the valuable suggestions and discussions. The authors are also thankful to Mr. Ghanashyam Shrivastav, the Head of Department of Chemistry, Mahendra Morang Adarsh Multiple Campus, Tribhuvan University, Biratnagar, Nepal for providing us the research facilities to conduct this research work.

\section{REFERENCES}

[1] Sokol V, Tomas R \& Tominic I, Conductometric Study of Ammonium Bromide in 2Butanol + Water Mixtures, Acta Chim. Slov., 56(2009)773.

[2] Janz G T \& Tomkins R P T, Non Aqueous Electrolytes Handbook, Academic Press: London.( 1972) Vol.1. 
[3] Lee J J \& Lee M D, Conductance of tetra alkyl ammonium halides in ethanol-water mixtures, Korean Journal of Chemical Engineering, 5(1)( 1988) 5.

[4] Lee M D \& Lee J J, Seoul Univ. Faculty papers, 4(c) (1975) 21.

[5] Chazhoor J S \& Radhakrishnan T P, Conductance of sodium nitrate in ethanol-water mixtures at $35^{\circ} \mathrm{C}$, Journal of Physical Chemistry, 60(1979)151.

[6] Bhattarai A \& Sah S K, Effects of Concentration and Relative Permittivity on the Transport Properties of Sodium Chloride in pure water and ethanol-water mixed solvent media, Research Journal of Chemical Sciences, 1(6) (2011)1.

[7] Bhattarai A \& Raut J, Conductometric Studies of Potassium Bromide in pure water and ethanol-water mixed solvent media, Journal of Alpine Chemistry, 2(2011)44.

[8] Bhattarai A \& Neupane S, Effects of Concentration and Solvent Composition on the electrical Conductivity of Sodium Bromide in Pure water and Ethanol-Water Mixed Solvent Media, First International Science Congress organized by International Science Congress Association, Indore, India, 24-25 December 2011.

[9] Lange N A \& Dean J A, Lange's Handbook of Chemistry, 10th ed. McGraw-Hill, New York.1967.

[10] Harned H S \& Owen B B, The physical chemistry of electrolytic solutions, Reinhold, New York. (1957) 234.

[11] Lind J E Jr, Zwolenik J J \& Fuoss R M, Calibration of Conductance Cells at 250 C with Aqueous Solutions of Potassium Chloride, Journal of American Chemical Society, 81(1959)1557.

[12] Das B \& Hazra D K, Studies on the Viscosities, Conductances, and Adiabatic Compressibilities of Some Tetraalkylammonium Perchlorates in 2-Methoxyethanol, Bulletin of Chemical Society of Japan, 65( 1992)3470.

[13] Das B \& Hazra D K, Conductometric, Viscometric, and Spectroscopic Investigations on the Solvation Phenomena of Alkali-Metal Ions and Ion pairs in 2-Methoxyethanol, Journal of Physical Chemistry, 99( 1995)269.

[14] Franks F \& Ives D J G, The structural properties of alcohol-water mixtures, Quartely Review, 20(1966) 1.

[15] Thakur S K \& Chauhan S, Ultrasonic Velocity and Allied parameters of drug Colimax in aqueous 1-propanol at 298.15 K, Journal of Chemical Pharmaceutical Research, $3(2)(2011) 657$.

[16] Syal V K, Thakur S K, Chauhan S \& Sharma P, Ultrasonic Velocity Studies of Drug Parvon-spas in Mixed Alcohol-Water Solvent Systems at 298.15 K, International Journal of Thermophysics, 26(2005)807.

[17] Bhattarai A, Chatterjee S K, Deo T K \& Niraula T P, Effects of Concentration, 
Temperature and Solvent Composition on the Partial Molar Volumes of Sodium Lauryl Sulfate in Methanol -Water mixed Solvent Media, Journal of Chemical Engineering Data, 56 (2011)3400.

[18] Bhattarai A, Nandi P \& Das B, The Effects of Concentration, Relative Permittivity and Temperature on the Transport Properties of Sodium Polystyrenesulphonate in Methanol-Water Mixed Solvent Media, Journal of Polymer Research, 13(2006) 475.

[19] Bhattarai A, Electrical Conductivity of Semidilute Solution of Sodium Polystyrenesulfonate in Methanol-Water Mixtures at Four Different Temperatures: The Scaling Theory Approach., Nepal Journal of Science and Technology, $9(2008) 163$.

[20] Bhattarai A, Sapkota D, Khanal M, Subedi N P \& Niraula T P, Conductance of Sodium Nitrate in methanol-water mixtures at different temperatures, Nepal Journal of Science and Technology, 12(2011) 187.

[21] Bhattarai A, Chatterjee S K \& Shah S K, Effects of Concentration, Temperature and Solvent Composition on the Conductivity of Potassium Nitrate in Methanol - Water mixed Solvent Media, Journal of Institute of Science and Technology, Tribhuvan University, 2012 (in press).

[22] Chatterjee A \& Das B, Electrical Conductances of Tetrabutylammonium Bromide, SodiumTetraphenylborate, and Sodium Bromide in Methanol (1) + Water (2) Mixtures at $(298.15,308.15$, and 318.15) K, Journal of Chemical Engineering Data, 51(2006)1352. 